\title{
Maintenance of high proliferation and multipotent potential of human hair follicle-derived mesenchymal stem cells by growth factors
}

\author{
XUEYAN ZHANG, YIMEI WANG, YUNHE GAO, XUEJUAN LIU, TINGTING BAI, MEIYING LI, \\ LISHA LI, GUANFAN CHI, HUI XU, FEILIN LIU, JIN YU LIU and YULIN LI
}

The Key Laboratory of Pathobiology, Ministry of Education, Jilin University, Changchun, Jilin 130021, P.R. China

Received October 31, 2012; Accepted January 4, 2013

DOI: $10.3892 /$ ijmm.2013.1272

\begin{abstract}
Cell therapy and cell-based tissue engineering is becoming increasingly important in regenerative medicine. Stem cells that are characterized by self-renewal, high proliferation and multiple differentiation potentials have attracted attention in cell-based regenerative medicine. Maintaining the aforementioned characteristics of stem cells is the first key step in cell-based regenerative medicine. Basic fibroblast growth factor (bFGF) is a well-known growth factor that efficiently maintains the self-renewal, high proliferation and multilineage differentiation potential of stem cells. Whether or not other growth factors, such as acidic fibroblast growth factor (aFGF) and epidermal growth factor (EGF) have similar effects has yet to be fully elucidated. Human hair follicle-derived mesenchymal stem cells (HF-MSCs) were obtained by organ culture. They exhibited surface markers of bone marrow mesenchymal stem cells as shown by positive staining for CD44, CD73, CD90 and CD105, and they also displayed trilineage differentiation potentials into adipocytes, chondrocytes and osteoblasts by cytochemistry and qRT-PCR. Flow cytometry analysis showed that up to $70 \%$ of HF-MSCs cultured in the presence of aFGF, bFGF or EGF stayed at the G0/G1 phase. Proliferation analysis showed that both bFGF and EGF at as low as $1 \mathrm{ng} / \mathrm{ml}$ and aFGF at above $5 \mathrm{ng} / \mathrm{ml}$ levels significantly increased the proliferation of HF-MSCs by cell counting. Consistent with proliferation analysis, immunofluorescence staining showed that more than $95 \%$ of HF-MSCs cultured in the presence of aFGF, bFGF and EGF were positively stained for proliferating cell nuclear antigen. HF-MSCs cultured in the presence of aFGF, bFGF or EGF retained marked trilineage differentiation potentials. By contrast, HF-MSCs cultured in the absence of bFGF, aFGF and EGF lost multipotency.
\end{abstract}

Correspondence to: Dr Yulin Li, The Key Laboratory of Pathobiology, Ministry of Education, Jilin University, 126 Xinmin Street, Changchun, Jilin 130021, P.R. China

E-mail: ylli@jlu.edu.cn

Key words: hair follicle, stem cell, epidermal growth factor, basic fibroblast growth factor, acidic fibroblast growth factor

\section{Introduction}

The hair follicle is one of the skin appendages, a mini organ that forms early in embryonic development as a result of epithelial-mesenchymal cell interactions. The occurrence and maintenance of hair follicle is related to more than 20 types of cells (1). The hair follicle is one of the few organs in the body with the ability to undergo cycles of degeneration and regeneration throughout life (2). It has been reported that multipotent stem cells, isolated from individual follicles, are similar to bone marrow mesenchymal stem cells since they express surface markers of mesenchymal stem cells and can differentiate into adipocytes, chondrocytes, osteoblasts, glial cells, melanocytes, smooth muscle cells and endothelial cells (3-5).

In addition, hair follicle allografts have not demonstrated immune rejection, suggesting that the engrafted hair follicles have low immunogenic properties (6). Therefore, hair follicle stem cells appear to be highly appropriate seed cells for tissue engineering and clinical application.

Self-renewal and multipotent differentiation are characteristics of stem cells. Since numerous undifferentiated stem cells are required for clinical applications, several laboratories have supplemented their expansion medium with growth factors to accelerate stem cell proliferation. Fibroblast growth factors (FGFs), are a family of growth factors involved in angiogenesis, wound healing, and embryonic development. The FGFs are heparin-binding proteins, and interactions with cell-surface associated heparan sulfate proteoglycans are essential for FGF signal transduction (7).

FGFs are key players in the processes of proliferation and differentiation of a wide variety of cells and tissues. Acidic fibroblast growth factor (aFGF) functions as a modifier of endothelial cell migration and proliferation, as well as an angiogenic factor. It acts as a mitogen for a variety of mesoderm- and neuroectoderm-derived cells in vitro $(8,9)$.

Basic fibroblast growth factor (bFGF) is a critical component of human embryonic stem cell culture medium and is necessary for the cells to remain in an undifferentiated state, although the mechanisms by which it does this are poorly defined. It is necessary in mouse-feeder cell dependent culture systems, as well as in feeder and serum-free culture systems $(10,11)$. 
Epidermal growth factor (EGF) is known to enhance migration and cell proliferation of bone marrow-derived mesenchymal stem cells while maintaining differentiation potential (8). Numerous studies have demonstrated that EGF and bFGF increase proliferation and modulate the differentiation potential of human adipose-derived stromal/stem cells (12-15).

Based on these observations, we hypothesized that the presence of aFGF, EGF and bFGF would enhance the proliferation and multipotent potential of human hair follicle-derived mesenchymal stem cells (HF-MSCs). The current study examined the effect of aFGF, EGF and bFGF with respect to HF-MSC proliferation and multipotent differentiation.

\section{Materials and methods}

Isolation and cultivation of human hair follicle stem cells. Human hair follicle stem cells were isolated from adult occipital and temporal hair follicles. The hair follicles were drawn off by cropped tweezers. After extensive washing with phosphate-buffered saline (PBS) containing antibioticantimycotic (Hyclone, USA), the hair follicles were transferred each into a single well of a 96-well culture plate, and cultured in $100 \mu 1$ of Dulbecco's modified Eagle's medium/F12 (DMEM/F-12) containing 10\% fetal bovine serum (FBS; Gibco, USA) and $1 \%$ antibiotic/antimycotic, supplemented with $10 \mathrm{ng} / \mathrm{ml}$ EGF and $10 \mathrm{ng} / \mathrm{ml} \mathrm{bFGF}$ to allow for cell migration onto the tissue culture plastic. The wells populated with cells originating from the dermal sheath or papilla and which had the morphological appearance of mesenchymal cells were selected, pooled and expanded. Expanded cells were cultured in DMEM/F-12 containing 10\% FBS and 1\% antibiotic/antimycotic and supplemented with $2 \mathrm{ng} / \mathrm{ml}$ bFGF. Prior to the proliferation assay, the cells were cultured in stromal medium (DMEM/F-12, 10\% FBS) for 7 days.

Adipogenic, osteogenic and chondrogenic differentiation of human hair follicle stem cells. Conditions to induce the differentiation of human hair follicle stem cells into adipocytes, chondrocytes, and osteoblasts were employed as previously described (2). Cells were grown in the adipogenic medium [high glucose DMEM (Gibco), 10\% FBS, $0.5 \mu \mathrm{M}$ IBXM, $1 \mu \mathrm{M}$ dexamethasone, $10 \mu \mathrm{M}$ insulin, $200 \mu \mathrm{M}$ indomethacin (Sigma, USA)] for 2 weeks, and then stained using Oil Red O (2).

The cells were cultured in the osteogenic medium [high glucose-DMEM, 10\% FBS, $50 \mu \mathrm{M}$ ascorbate-2-phosphate, $0.1 \mu \mathrm{M}$ dexamethasone, $10 \mathrm{mM} \beta$-glycerolphosphate (Sigma)] for 2 and 4 weeks. Following differentiation for 2 weeks, the alkaline phosphatase (ALP) enzymatic activity (2), Alizarin Red staining and the von Kossa staining (2) was performed after 4 weeks of culture to examine osteogenic differentiation.

For chondrogenic differentiation, cell spheres of HF-MSCs were generated by adding $20 \mathrm{ml}$ of $8 \times 10^{6} \mathrm{cell} / \mathrm{ml}$ HF-MSCs drop wise in non-tissue-culture-treated 24-well plates. After $4 \mathrm{~h}$ of incubation at $37^{\circ} \mathrm{C}$ and $10 \% \mathrm{CO}_{2}$, the medium was changed to the chondrogenic differentiation medium: high glucose DMEM with $10 \%$ FBS, $6.25 \mu \mathrm{M}$ insulin, $10 \mathrm{ng} / \mathrm{ml}$ transforming growth factor- $\beta 1$ (TGF- $\beta 1$; Sigma), and $50 \mu \mathrm{M}$ of ascorbate-2-phosphate. The culture medium was replenished every 3 days for 2 weeks. At that time, cell spheres of
HF-MSCs were fixed in $10 \%$ buffered formalin phosphate (Fisher Scientific) and embedded in paraffin. The tissue sections were used for Alcian blue staining and collagen II immunohistochemistry (2).

Real-time PCR. After the differentiation of human hair follicle stem cells into adipocytes, chondrocytes, and osteoblasts, the total RNA was extracted from differentiated cells using TRI-Reagent (Sigma), according to the manufacturer's instructions. Total RNA was reverse transcribed by RNA PCR kit (AMV) Ver.3.0 (Takara, Dalian, China). For quantitative determination, the real-time PCR was performed in the Applied Biosystems 7500 sequence detection system (Applied Biosystems, Foster City, CA, USA) using SYBR ${ }^{\circledR}$-Green (Roche Diagnostics) as a double-strand DNA-specific binding dye, according to the manufacturer's instructions. Samples were amplified using specific primers to ap2, peroxisome proliferator-activated receptor $\gamma 2$ (PPAR $\gamma 2)$, ALP, runt-related transcription factor 2 (RUNX2), osteocalcin (OC), collagen II, SOX9 and $\beta$-actin. $\beta$-actin was used as internal standard, and relative expression was calculated according to the $\Delta \mathrm{Ct}$ method. The result of real-time PCR was represented as fold increase with respect to the control sample (construct grown in DMEM/ F-12 containing 10\% FBS and 1\% antibiotic/antimycotic and supplemented with $2 \mathrm{ng} / \mathrm{ml} \mathrm{bFGF})$. The PCR oligonucleotide primers were $(34,35)$ : ap2 (F, 5'-AAAGAAGTAGG AGTGGGCTTTGC-3' and R, 5'-CCCCATTCACACTGAT GATCAT-3'); PPAR $\gamma 2$ (F, 5'-AGGCGAGGGCGATCTTG-3' and R, 5'-CCCATCATTAAGGAATTCATGTCATA-3'); SOX9 (F, 5'-TTCATGAAGATGACCGACGA-3' and R, 5'-GTCCAG TCGTAGCCCTTGAG-3'); collagen II (F, 5'-AGAGACCTG AACTGGGCAGA-3' and R, 5'-TGACACGGAGTAGCACC ATC-3'); ALP (F, 5'-CCAACGTGGCTAAGAATGTCATC-3' and R, 5'-TGGGCATTGGTGTTGTACGTC-3'); RUNX2 (F, 5'-TGGTTAATCTCCGCAGGTCAC-3' and R, 5'-ACTGTGCT GAAGAGGCTGTTTG-3'); OC(F, 5'-CCATGAGAGCCCTCA CACTCC-3' and R, 5'-GGTCAGCCAACTCGTCACAGTC-3'); $\beta$-actin (F, 5'-CATGTACGTTGCTATCCAGGC-3' and R, 5'-CTCCTTAATGTCACGCACGAT-3').

Effect of growth factors on human hair follicle stem cell proliferation. Following culture in stromal medium (DMEM/ F-12, 10\% FBS) for 7 days, the human hair follicle stem cells were harvested by trypsin digestion and replated at a density of 10,000 cells/well in 6-well plates in stromal medium (2). After $24 \mathrm{~h}$ to allow for adherence, the stromal medium was converted to DMEM/F-12 containing 10\% FBS and 1\% antibiotic/antimycotic and supplemented with $\operatorname{EGF}(0,1.0,2.0,5.0$, 10 or $20 \mathrm{ng} / \mathrm{ml})$ or bFGF $(0,1.0,2.0,5.0,10$ or $20 \mathrm{ng} / \mathrm{ml})$ or aFGF $(0,1.0,3.0,5.0,10$ or 20,50 or $100 \mathrm{ng} / \mathrm{ml})$. Cells used in proliferation assays were maintained under these conditions for 7 days.

Cell counting ( $n=3$ donors). Cell proliferation was determined on passages 9-11 human hair follicle stem cells after 7 days of conditioning with varying concentrations of EGF, bFGF and aFGF. Cells from individual wells of a 6-well plate were harvested by digestion with $0.25 \%$ trypsin/0.01\% EDTA. An aliquot of cells was stained with trypan blue, and total number of cells/well was measured using a hemocytometer. 

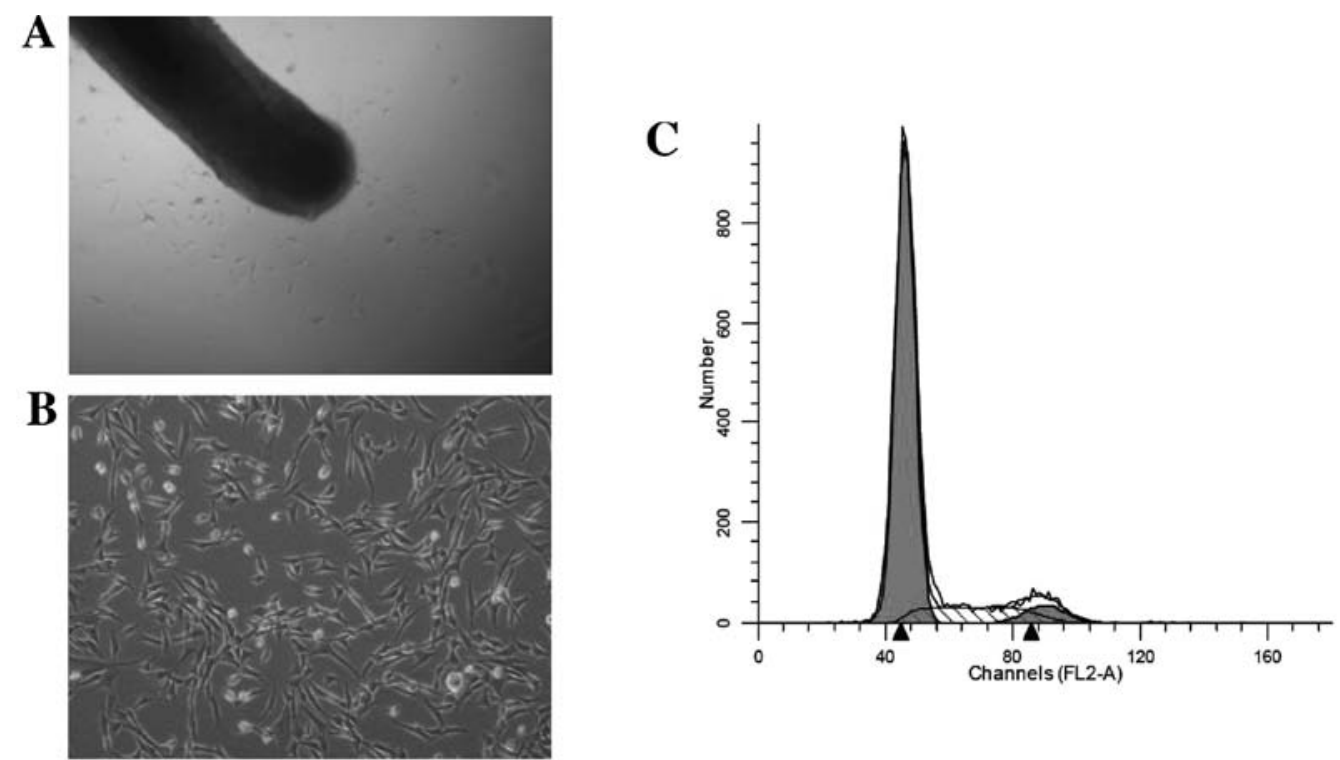

Figure 1. Biological characteristics of human hair follicle-derived mesenchymal stem cells (HF-MSCs). (A) Cells migrating out of the outer root sheath and dermal papilla. (B) HF-MSCs had a fibroblast-like cell morphology. (C) Flow cytometry for cell cycle analysis. The HF-MSCs (79.57\%) were in the G0/G1 phase, $6.03 \%$ of the cells were in the G2 and $14.40 \%$ of the cells were in the S phase. Magnification, (A) x400 and (B) x 200 .

Cell cycle analysis. After the cell counting, the optimal concentration of each individual growth factor was determined. The cells were cultured in stromal medium (DMEM/F-12, 10\% FBS) in the presence of each individual optimal concentration of EGF, bFGF and aFGF, respectively, for 7 days followed by trypsinization with $1 \mathrm{ml}$ of trypsin. Five milliliters PBS was added to the digest and the cells were spun down at $800 \mathrm{rpm}$ for $5 \mathrm{~min}$. Five milliliters of $70 \% \mathrm{EtOH}$ (cold) were added to the cell pellets. The cells were vortexed gently and incubated in $\mathrm{EtOH}$ at $4^{\circ} \mathrm{C}$ overnight. Next day, the cells were spun down at $800 \mathrm{rpm}$ for $5 \mathrm{~min}$ and the cell pellets were washed once in PBS for $1 \mathrm{~min}$ and incubated with $150 \mu \mathrm{l}$ RNAse $(5 \mu \mathrm{g} / \mathrm{ml})$ at $37^{\circ} \mathrm{C}, 5 \% \mathrm{CO}_{2}$ for $45 \mathrm{~min}$. At the end of the incubation, $350 \mu \mathrm{l}$ of propidium iodine (PI; Dingguo, Beijing, China) were added and the cells were incubated at $4^{\circ} \mathrm{C}$ for $30 \mathrm{~min}$ and analyzed immediately following the completion of the incubation to prevent cells from clumping.

Proliferating cell nuclear antigen (PCNA) immunohistochemistry. Cells were seeded in a 24-well tissue culture plate at a density of 5,000 cells/well and were cultured in the DMEM-F12 medium deprived of any growth factors for 7 days. Subsequently, individual growth factors (EGF, bFGF or aFGF) at optimal concentrations were added to the culture medium and the cells were cultured for another 7 days. At the end of the cultivation, the medium was aspirated and the cells were washed 3 times with PBS, fixed in 4\% paraformaldehyde at room temperature (RT) for $10 \mathrm{~min}$. Following fixation, the cells were washed 3 times with PBS and permeabilized in $0.1 \%$ Triton X-100 at RT for 10 min, blocked with $10 \%$ FBS/PBS for $30 \mathrm{~min}$. They were then incubated with mouse anti-human PCNA antibody (1:200 dilution, at RT for $30 \mathrm{~min}$; Millipore) in blocking solution (0.01\% Triton X-100 in $10 \%$ FBS) at $4^{\circ} \mathrm{C}$ overnight. After 3 washes in PBS, the cells were incubated with Alexa Fluor 488-conjugated goat anti-mouse antibody (1:200 dilution, at RT for 60 min in dark; Abcam), washed once with PBS and incubated with Hoechst 33342 (1:10,000, at RT, 2 min in dark; Abcam) to stain the nuclei. Cells stained only with secondary antibody served as the negative control.

\section{Results}

Isolation and cultivation of human hair follicle stem cells. After being cultured for one week, mesenchymal cells were observed migrating from the hair follicles. Cells from individual wells were harvested by $0.25 \%$ trypsin in $0.01 \%$ EDTA. Following centrifugation at $1,000 \mathrm{rpm}$ for $5 \mathrm{~min}$, the cells were transferred into the wells of 24-well plates. The mesenchymal cells migrated out of the outer root sheath and dermal papilla (Fig. 1A) and had fibroblast-like cell morphology (Fig. 1B).

Cell cycle analysis and multilineage differentiation potential of HF-MSCs. Since the nuclear DNA content reflects the position of a cell within a cell cycle, flow cytometric analysis of nuclear DNA content was performed on cells following isolation. At passages P9-11, 80\% of the HF-MSCs were in the G0/ G1 phase, and $14 \%$ of cells were in the S phase (Fig. 1C). This result suggested that the cells we obtained demonstrated the slow cycling that characterizes stem cells.

Isolated HF-MSCs were cultured under specific conditions and subsequently examined by functional differentiation assays. We studied the potential of these cells to differentiate into multiple cell lineages, in particular, chondrocytes, adipocytes and osteocytes, as previously described in Materials and methods.

Adipogenic differentiation was assessed by Oil Red O staining. After 14 days of culture in adipogenic medium, the HF-MSCs showed positive staining, with single adipocytic multivacuolar cells secreting lipid droplets (Fig. 2A). The same cells maintained in control medium (DMEM/F-12, $10 \%$ FBS and $2 \mathrm{ng} / \mathrm{ml} \mathrm{bFGF}$ ) exhibited almost no lipid deposits (Fig. 2B).

The osteogenic differentiation potential of HF-MSCs was examined by testing ALP enzymatic activity, Alizarin Red 
$\mathbf{A}$

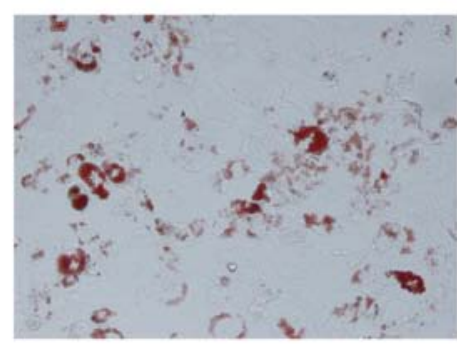

B

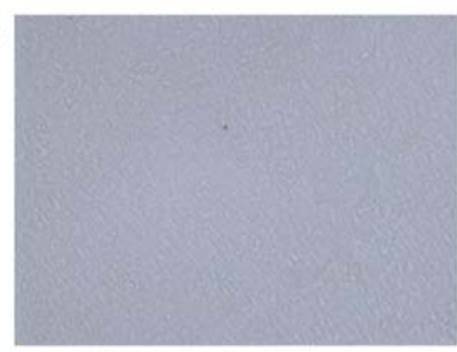

$\mathbf{C}$ ALP

Von Kossa

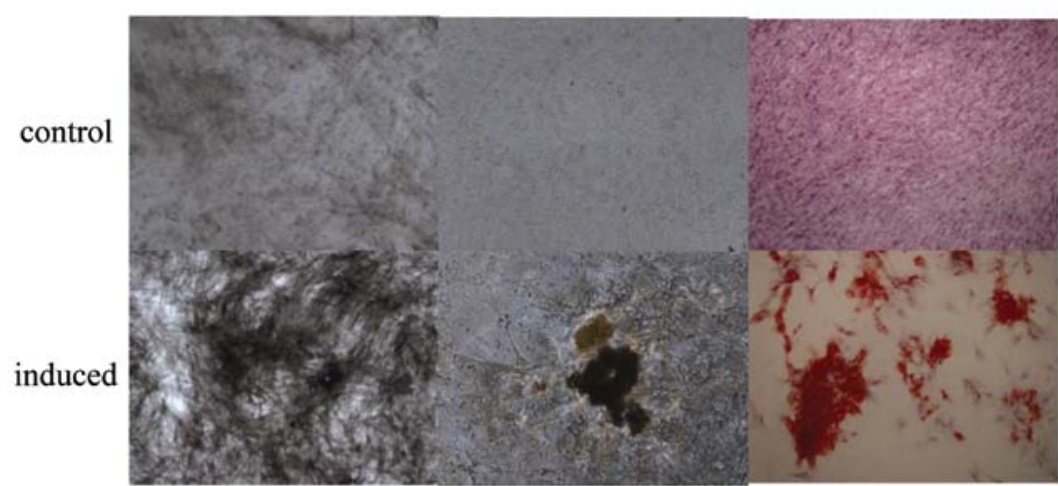

D

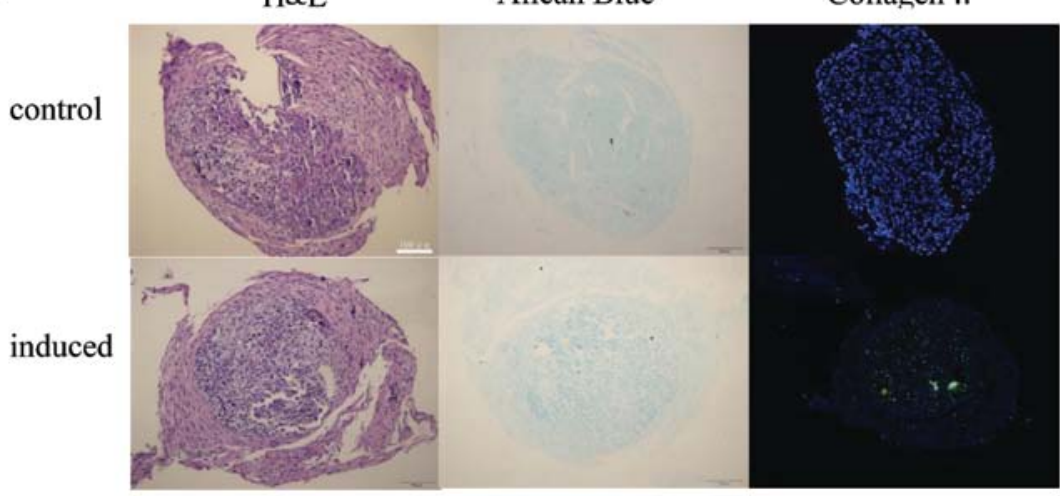

Figure 2. Human hair follicle-derived mesenchymal stem cells (HF-MSCs) demonstrated adipogenic, osteogenic and chondrogenic differentiation potential. HF-MSCs were cultured in the (A and B) adipogenic, (C) osteogenic or (D) chondrogenic differentiation medium or control medium. Oil Red O staining of HF-MSCs that were treated with the (A) adipogenic or (B) control medium. Magnification, (A and B) x200, (C) ALP x100, von Kossa and Alizarin Red x400. ALP, alkaline phosphatase.

staining and the von Kossa staining. The cells demonstrated ALP enzymatic activity and calcium deposition. The same cells maintained in control medium had an absence of calcium deposits (Fig. 2C).

The ability to undergo chondrogenic differentiation was assessed by Alcian blue staining for proteoglycans. Collagen II was detected by immunohistochemistry (Fig. 2D).

Adipogenic, osteogenic and chondrogenic differentiation was also assessed by qRT-PCR. Expression levels of ap2 and PPAR $\gamma 2$ were analyzed for adipogenic differentiation. Expression levels of ALP, RUNX2 and OC were analyzed for osteogenic differentiation, and expression levels of collagen II, SOX9 were analyzed for chondrogenic differentiation. RNA extracted from HF-MSCs following adipogenic, osteogenic and chondrogenic differentiation showed expression of all these lineage-specific genes (Fig. 2E) The expression of the $\beta$-actin housekeeping gene was assessed in all samples to analyze the integrity of the amplified cDNA.
Effect of growth factors on the proliferation of human hair follicle stem cells. After 7 days of conditioning with varying concentrations of bFGF, EGF and aFGF, the total number of human hair follicle stem cells per well was determined using a hemocytometer. Proliferation analysis showed that both EGF and bFGF at as low as $1 \mathrm{ng} / \mathrm{ml}$ and aFGF at above $5 \mathrm{ng} / \mathrm{ml}$ levels significantly increased the proliferation of HF-MSCs. $\mathrm{aFGF}$ and bFGF acted in a synergistic manner, but concentrations of EGF between 1 and $20 \mathrm{ng} / \mathrm{ml}$ had no significant effect on proliferation, relative to the control without growth factor (Fig. 3A-C). The optimal concentration of the growth factors for stimulation of HF-MSCs proliferation was $20 \mathrm{ng} / \mathrm{ml} \mathrm{bFGF}$, $1 \mathrm{ng} / \mathrm{ml}$ EGF and $100 \mathrm{ng} / \mathrm{ml}$ aFGF. These concentrations were used in all further experiments.

Consistent with proliferation analysis, immunofluorescence staining showed that $>95 \%$ of the HF-MSCs cultured in the presence of aFGF, $\mathrm{bFGF}$ and EGF were positively stained for PCNA (Fig. 3D). 

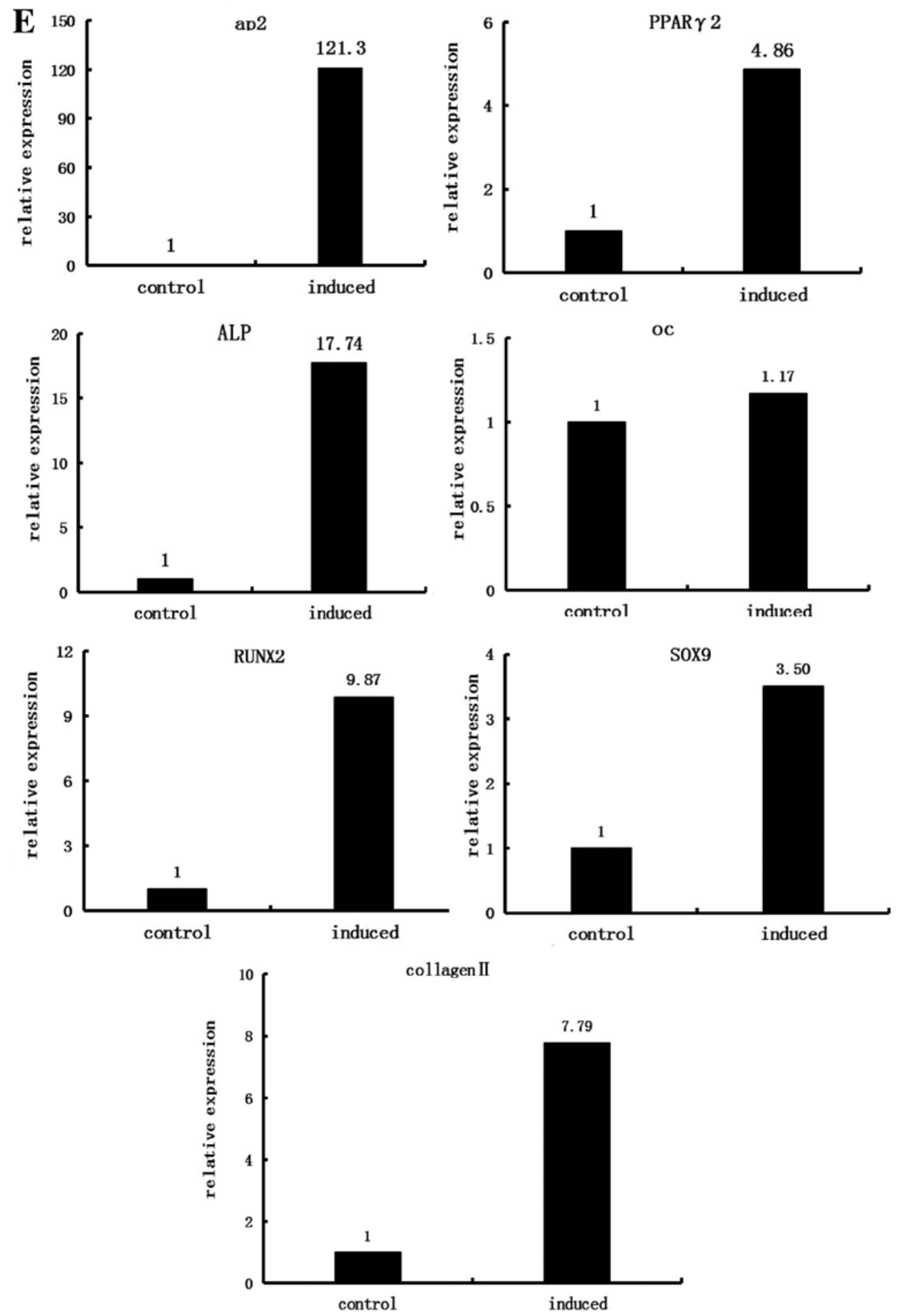

Figure 2. Continued. (E) Adipogenic, osteogenic and chondrogenic differentiation was also assessed by qRT-PCR. Expression levels of ap2 and PPAR 2 were analyzed for adipogenic differentiation. Expression levels of OC, RUNX2 and ALP were analyzed for osteogenic differentiation, and expression levels of Col II and SOX9 were analyzed for chondrogenic differentiation. PPAR $\gamma 2$, peroxisome proliferator-activated receptor $\gamma 2$; ALP, alkaline phosphatase; OC, osteocalcin; RUNX2, runt-related transcription factor 2.

Furthermore, flow cytometric analysis showed that up to $70 \%$ of HF-MSCs cultured in the presence of aFGF, bFGF or EGF remained at the G0/G1 phase, and that the proliferation index (PI) significantly increased relative to controls (Fig. 3E). The results of PCNA and PI analyses demonstrated that the addition of bFGF, EGF and aFGF to the cell culture medium increased the proliferation of HF-MSCs.
To test whether the cells cultured in the presence of growth factors could display the multilineage differentiation potential, we replaced the culture medium after 7 days of conditioning with $20 \mathrm{ng} / \mathrm{ml} \mathrm{bFGF,} 1 \mathrm{ng} / \mathrm{ml}$ EGF, $100 \mathrm{ng} / \mathrm{ml}$ aFGF, with induction medium. Indeed, we found that the cells could differentiate into fat, bone, or cartilage cells under appropriate differentiation conditions (Fig. 4). 

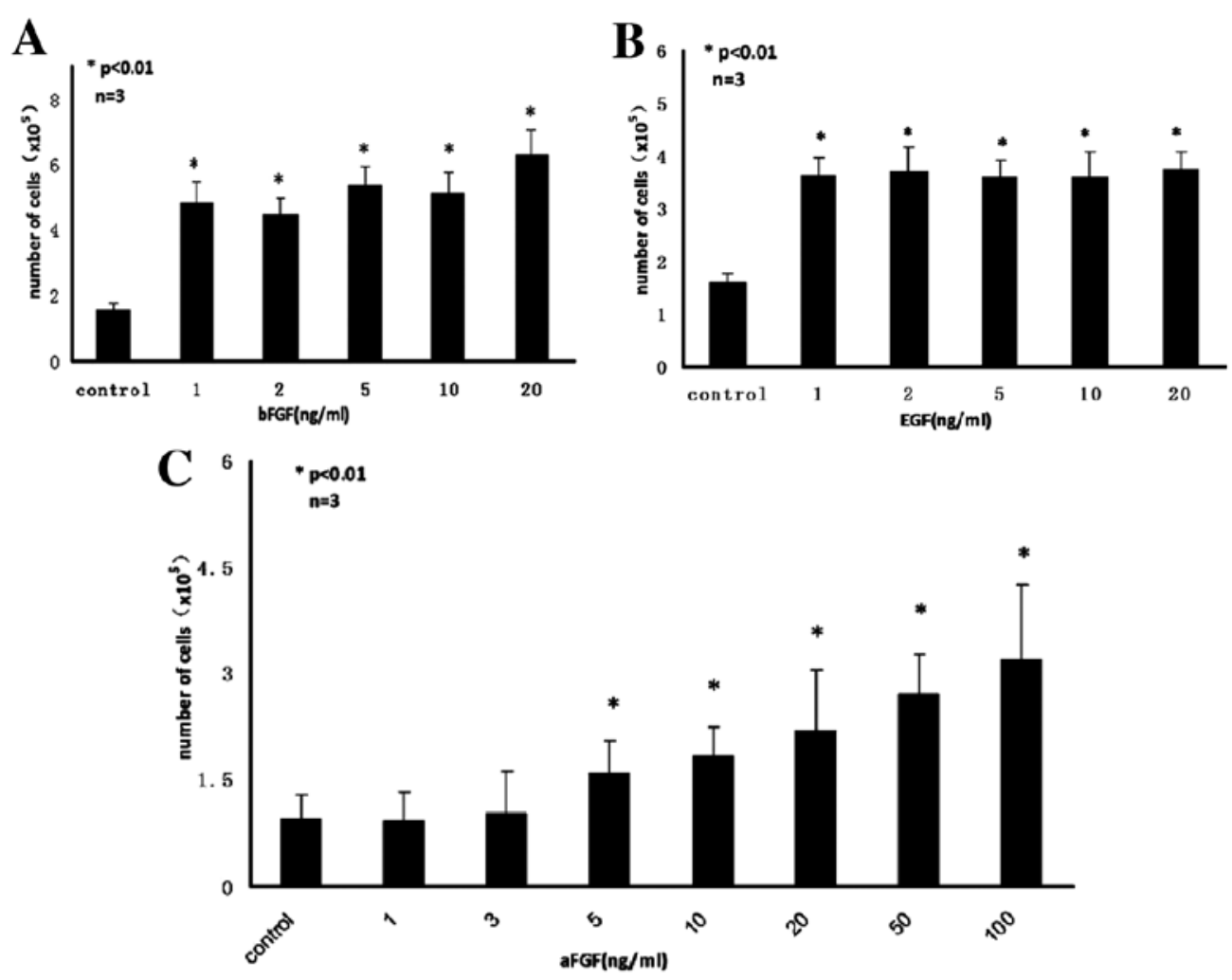

D
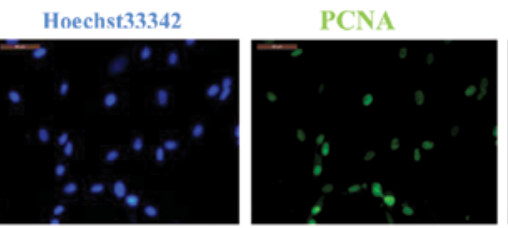

Merge
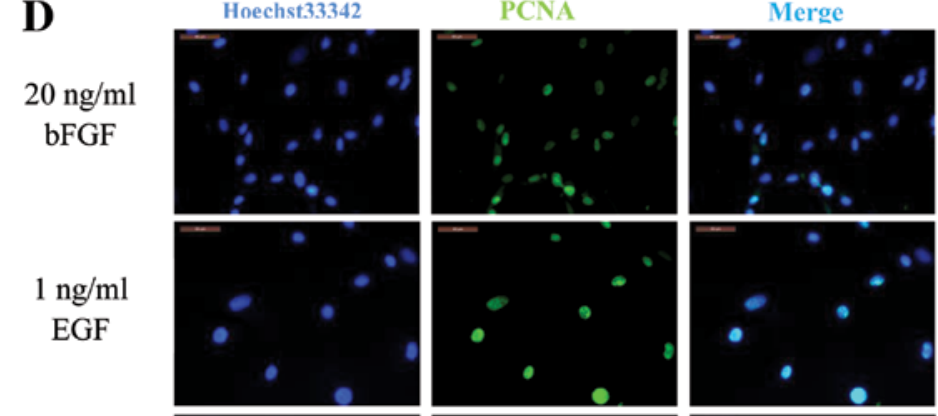

$1 \mathrm{ng} / \mathrm{ml}$
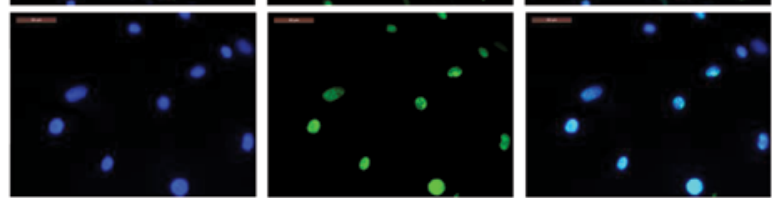

$100 \mathrm{ng} / \mathrm{ml}$

aFGF
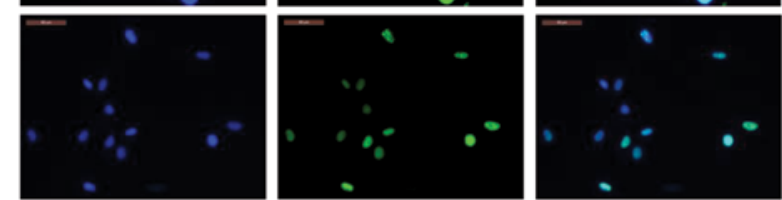

control
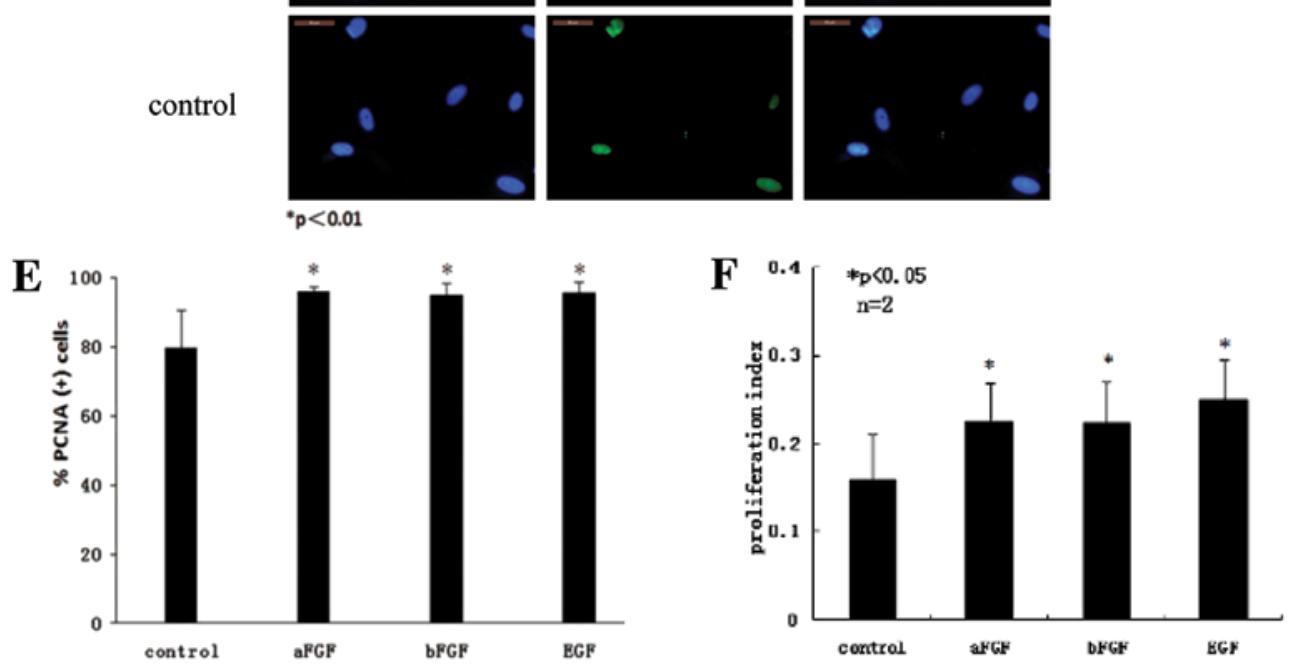

Figure 3. Effect of growth factors on human hair follicle stem cell proliferation. (A-C) Cells were cultured in the presence or absence of (A) bFGF, (B) EGF or (C) aFGF and at the indicated times trypsinized, counted and re-plated at the same density. The cumulative cell number was plotted as mean \pm SD of 3 independent experiments $(n=3)$. (D and E) Immunofluorescence staining showed that $>95 \%$ of human hair follicle-derived mesenchymal stem cells (HF-MSCs) cultured in the presence of aFGF, bFGF and EGF were positively stained for proliferating cell nuclear antigen $(\mathrm{PCNA})$. $(\mathrm{F}) \mathrm{Proliferation}$ index $(\mathrm{PI})=(\mathrm{G} 2+\mathrm{S}) /$ $\mathrm{G} 1+\mathrm{S}+\mathrm{G} 2 \times 100 \%$. (D) Magnification, $\mathrm{x} 400$. bFGF, basic fibroblast growth factor; EGF, epidermal growth factor; aFGF, acidic fibroblast growth factor. 

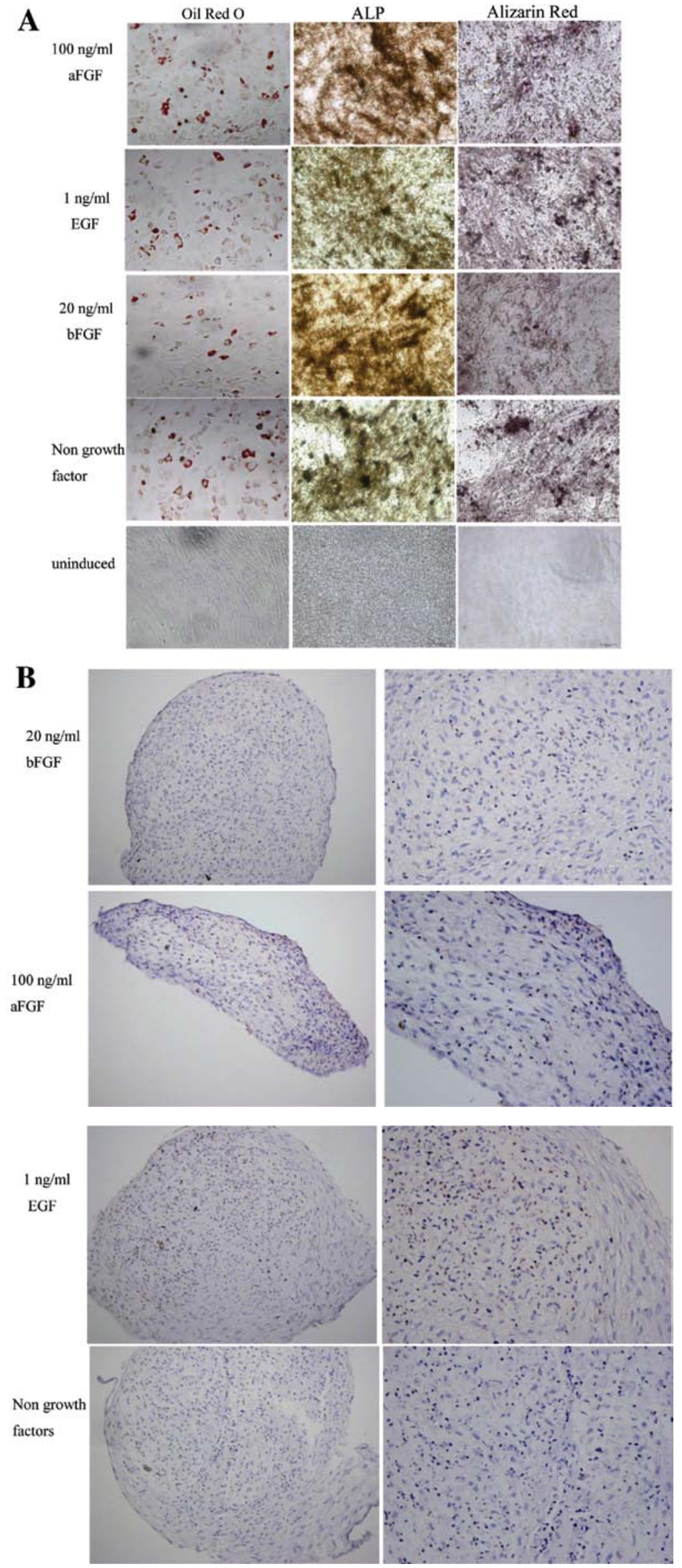

Figure 4. Human hair follicle-derived mesenchymal stem cells (HF-MSCs) cultured with growth factors retained their adipogenic, osteogenic and chondrogenic differentiation potential. After 7 days of conditioning with $20 \mathrm{ng} / \mathrm{ml} \mathrm{bFGF,} 1 \mathrm{ng} / \mathrm{ml} \mathrm{EGF}, 100 \mathrm{ng} / \mathrm{ml} \mathrm{aFGF}$ and control without growth factors, the medium was changed to differentiation medium. HF-MSCs were cultured in the (A) adipogenic and osteogenic or (B) chondrogenic medium. Magnification, (A) x200; (B) left, x200 and right, $\mathrm{x} 400$. ALP, alkaline phosphatase; bFGF, basic fibroblast growth factor; EGF, epidermal growth factor; aFGF, acidic fibroblast growth factor. 


\section{Discussion}

Our results are consistent with several previous studies that have demonstrated the multipotency of rat or human skin dermal fibroblasts (16-20). It has been established that the bulge area of the hair follicle is a rich source of epidermal stem cells (21-24). The present study further supports these data by showing that HF-MSCs express CD44, CD73, CD90 and CD105 which are the surface markers that characterize MSCs. HF-MSCs have the potential to differentiate into multiple cell lineages, particularly chondrocytes, adipocytes and osteocytes (2), suggesting that HF-MSCs may be highly similar to MSCs derived from the bone marrow, adipose tissue, or other organs. Mainly, the hair follicle may be a readily accessible source of autologous human MSCs that can be used for tissue engineering and regenerative medicine.

The present study demonstrated that the use of aFGF, EGF and bFGF supplementation during the expansion culture of HF-MSCs improves their proliferation rate yet preserves their significant trilineage differentiation potentials. It has been demonstrated that EGF can increase the expansion of BMSCs for in vivo transplantation (14) and, if added subsequent to induction, enhanced adipogenesis (25). Moreover, EGF had notable effects on the growth and development of human adipose-derived stromal/stem cells at physiological concentrations $(0.5-2 \mathrm{ng} / \mathrm{ml})(13)$. Our results support the original studies which showed that EGF can increase the proliferation of HF-MSCs. Moreover, when $5 \mathrm{ng} / \mathrm{ml}$ EGF was added into the culture medium for 3 weeks, individual cells showed positive Oil Red O staining without culturing in adipogenic medium. Several studies have shown that bFGF increases proliferation and prevents differentiation of BM-MSCs (hMSCs) (26-28) and embryonic stem cells (10). Furthermore, bFGF preconditioning enhances the differentiation potential of the BMSCs $(28,29)$. Our results showed that aFGF is similar to bFGF in its ability to stimulate proliferation, but compared with bFGF the necessary concentration of aFGF was higher to achieve a similar proliferation rate.

It remains to be determined how EGF, aFGF and bFGF increase HF-MSC proliferation. They may act as downstream elements in its signal transduction pathway such as the FGF, the BMPs and the classic Wnt signaling pathway (30-33). Thus, further studies will focus on fully characterizing the in vitro and in vivo effects of EGF and FGFs.

\section{Acknowledgements}

This study was supported by the State Key Development Program of Basic Research of China (211CB606200), the National Natural Science Foundation of China (30930026/ C100101), the Science and Technology Planning Project of Jilin Province, China (200905180), the National Natural Science Foundation of China (31040028). The authors thank Willam Orr for the valuable editorial assistance.

\section{References}

1. Park IH, Zhao R, West JA, et al: Reprogramming of human somatic cells to pluripotency with defined factors. Nature 451: 141-146, 2008
2. Liu JY, Peng HF, Gopinath S, Tian J and Andreadis ST: Derivation of functional smooth muscle cells from multipotent human hair follicle mesenchymal stem cells. Tissue Eng Part A 16: 2553-2564, 2010.

3. Hoogduijn MJ, Gorjup E and Genever PG: Comparative characterization of hair follicle dermal stem cells and bone marrow mesenchymal stem cells. Stem Cell Dev 15: 49-60, 2006.

4. Jahoda CA, Whitehouse J, Reynolds AJ and Hole N: Hair follicle dermal cells differentiate into adipogenic and osteogenic lineages. Exp Dermatol 12: 849-859, 2003.

5. Rufaut NW, Goldthorpe NT, Wildermoth JE and Wallace OA: Myogenic differentiation of dermal papilla cells from bovine skin. J Cell Physiol 209: 959-966, 2006.

6. Jahoda CA, Reynolds AJ, Chaponnier C, Forester JC and Gabbiani G: Smooth muscle alpha-actin is a maker for hair follicle dermis in vivo and in vitro. J Cell Sci 99: 627-636, 1991.

7. Lin X, Buff EM, Perrimon N and Michelson AM: Heparan sulfate proteoglycans are essential for FGF receptor signaling during Drosophila embryonic development. Development 126: 3715-3723, 1999.

8. Böhlen P, Esch F, Baird A and Gospodarowicz D: Acidic fibroblast growth factor (FGF) from bovine brain: aminoterminal sequence and comparison with basic FGF. EMBO J 4: 1951-1956, 1985.

9. Gospodarowicz D, Massoglia S, Cheng J and Fujii DK: Effect of fibroblast growth factor and lipoproteins on the proliferation of endothelial cells derived from bovine adrenal cortex, brain cortex, and corpus luteum capillaries. J Cell Physiol 127: 121-136, 1986.

10. Vallier L, Alexander M and Pedersen RA: Activin/Nodal and FGF pathways cooperate to maintain pluripotency of human embryonic stem cells. J Cell Sci 118: 4495-4509, 2005.

11. Wang G, Zhang H, Zhao Y, Li J, Cai J, Wang P, Meng S, Feng J, Miao C, Ding M, Li D and Deng H: Noggin and bFGF cooperate to maintain the pluripotency of humanembryonic stem cells in the absence of feeder layers. Biochem Biophys Res Commun 330: 934-942, 2005.

12. Butterwith SC, Peddie CD and Goddard C: Regulation of adipocyte precursor DNA synthesis by acidic and basic fibroblast growth factors: interaction with heparin and other growth factors. J Endocrinol 137: 369-374, 1993.

13. Hauner H, Röhrig K and Petruschke T: Effects of epidermal growth factor (EGF), platelet-derived growth factor (PDGF) and fibroblast growth factor (FGF) on human adipocyte development and function. Eur J Clin Invest 25: 90-96, 1995.

14. Tamama K, Fan VH, Griffith LG, Blair HC and Wells A: Epidermal growth factor as a candidate for ex vivo expansion of bone marrow-derived mesenchymal stem cells. Stem Cells 24: 686-695, 2006.

15. Zaragosi LE, Ailhaud G and Dani C: Autocrine fibroblast growth factor 2 signaling is critical for self-renewal of human multipotent adipose-derived stem cells. Stem Cells 24: 2412-2419, 2006.

16. Toma JG, Akhavan M, Fernandes KJ, Barnabé-Heider F, Sadikot A, Kaplan DR and Miller FD: Isolation of multipotent adult stem cells from the dermis of mammalian skin. Nat Cell Biol 3: 778-784, 2001.

17. Fernandes KJ, McKenzie IA, Mill P, et al: A dermal niche for multipotent adult skin-derived precursor cells. Nat Cell Biol 6: 1082-1093, 2004.

18. Toma JG, McKenzie IA, Bagli D and Miller FD: Isolation and characterization of multipotent skin-derived precursors from human skin. Stem Cells 23: 727-737, 2005.

19. Chen FG, Zhang WJ, Bi D, Liu W, Wei X, Chen FF, Zhu L, Cui L and Cao Y: Clonal analysis of nestin(-) vimentin(+) multipotent fibroblasts isolated from human dermis. J Cell Sci 120: 2875-2883, 2007.

20. Lorenz K, Sicker M, Schmelzer E, Rupf T, Salvetter J, SchulzSiegmund M and Bader A: Multilineage differentiation potential of human dermal skin-derived fibroblasts. Exp Dermatol 17: 925-932, 2008.

21. Cotsarelis G, Sun TT and Lavker RM: Label-retaining cells reside in the bulge area of pilosebaceous unit: implications for follicular stem cells, hair cycle, and skin carcinogenesis. Cell 61: 1329-1337, 1990.

22. Morris RJ and Potten CS: Highly persistent label-retaining cells in the hair follicles of mice and their fate following induction of anagen. J Invest Dermatol 112: 470-475, 1999.

23. Tumbar T, Guasch G, Greco V, Blanpain C, Lowry WE, Rendl M and Fuchs E: Defining the epithelial stem cell niche in skin. Science 303: 359-363, 2004. 
24. Morris RJ, Liu Y, Marles L, Yang Z, Trempus C, Li S, Lin JS Sawicki JA and Cotsarelis G: Capturing and profiling adult hair follicle stem cells. Nat Biotechnol 22: 411-417, 2004.

25. Adachi H, Kurachi H, Homma H, et al: Epidermal growth factor promotes adipogenesis of 3T3-L1 cell in vitro. Endocrinology 135: 1824-1830, 1994.

26. Tsutsumi S, Shimazu A, Miyazaki K, Pan H, Koike C, Yoshida E, Takagishi K and Kato Y: Retention of multilineage differentiation potential of mesenchymal cells during proliferation in response to FGF. Biochem Biophys Res Commun 288: 413-419, 2001.

27. Solchaga LA, Penick K, Porter JD, Goldberg VM, Caplan AI and Welter JF: FGF-2 enhances the mitotic and chondrogenic potentials of human adult bone marrow-derived mesenchymal stem cells. J Cell Physiol 203: 398-409, 2005.

28. Martin I, Muraglia A, Campanile G, Cancedda R and Quarto R: Fibroblast growth factor-2 supports ex vivo expansion and maintenance of osteogenic precursors from human bone marrow. Endocrinology 138: 4456-4462, 1997.

29. Stewart AA, Byron CR, Pondenis H and Stewart MC: Effect of fibroblast growth factor- 2 on equine mesenchymal stem cell monolayer expansion and chondrogenesis. Am J Vet Res 68: 941-945, 2007.
30. Itoh $\mathrm{N}$ and Ornitz DM: Evolution of the Fgf and Fgfr gene families. Trends Genet 20: 563-569, 2004.

31. Itoh N and Ornitz DM: Functional evolutionary history of the mouse Fgf gene family. Dev Dyn 237: 18-27, 2008.

32. Thisse B and Thisse C: Functions and regulations of fibroblast growth factor signaling during embryonic development. Dev Biol 287: 390-402, 2005.

33. Mikels AJ and Nusse R: Wnts as ligands: processing, secretion and reception. Oncogene 25: 7461-7468, 2006.

34. Santiago-Mora R, Casado-Díaz A, De Castro MD and Quesada-Gómez JM: Oleuropein enhances osteoblastogenesis and inhibits adipogenesis: the effect on differentiation in stem cells derived from bone marrow. Osteoporos Int 22: 675-684, 2011.

35. Choi KH, Choi BH, Park SR, Kim BJ and Min BH: The chondrogenic differentiation of mesenchymal stem cells on an extracellular matrix scaffold derived from porcine chondrocytes. Biomaterials 31: 5355-5365, 2010. 